\title{
ANAEROBIC DECOLORIZATION OF AN AZO DYE BY A MIXED CULTURE
}

\author{
ISOLINA CABRAL GONÇALVES ${ }^{\mathrm{a}, *}$, MARIA ISABEL A. FERRA ${ }^{\mathrm{a}}$ and \\ MARIA TERESA AMORIM ${ }^{\mathrm{b}}$
}

\author{
${ }^{a}$ University of Beira Interior, Chemical Department, 6200 Covilhã, Portugal; \\ bUniversity of Minho, Engineering Textile Department, Quinta da Veiga, Azurém, \\ 4800 Guimarães, Portugal
}

(Received 3 April 2000; Revised 21 July 2000)

Wool dyeing wastewater contains xenobiotic compounds that can be removed by biotechnological processes. Studies on various dyes showed that anaerobic processes are suitable to alter azo dyes as a first step of the biodegradation process. These compounds are reduced by anaerobic consortia to aromatic amines and its ultimate degradation can be achieved by a further aerobic treatment.

Studies on degradation rate of an wool acid dye were performed in batch systems inoculated with anaerobic biomass. A commercial diazo dye, Acid Red 73, was added to the synthetic medium in which glucose was used as sole carbon source.

Results indicated that the Acid Red 73 was partially degraded by a mixed culture of anaerobic bacteria and a decolorization of $90 \%$ was obtained. Kinetics studies on removal of the colour showed that the decolorization rate was several times faster than the degradation rate of glucose for a range of dye concentrations between $60 \mathrm{mg} / \mathrm{L}$ and $400 \mathrm{mg} / \mathrm{L}$. A first order kinetic model was used for dye concentrations up to $200 \mathrm{mg} / \mathrm{L}$. For higher concentrations a model similar to the Michaelis-Menten equation was better fitted to the experimental data.

Keywords: Textile dyes; anaerobic batch reactors; kinetics; biodegradation

\section{INTRODUCTION}

Azo dyes constitute by far the largest number of acid dyes and include the majority of red, yellow, orange, brown and black hues. They range from

\footnotetext{
*Corresponding author. Fax: 351275 319730; E-mail: imscg@yahoo.com.
} 
relatively simple low molecular weight dyes, monoazo dyes as Acid Orange 7 , to quite complex molecules that generally possess a high affinity to wool and nylon, as diazo, triazo and polyazo compounds.

In order to respond to consumer demands for textile goods these compounds present a high colour stability and are, in general, resistant to biological degradation (Michaelis et al., 1985; 1986). Most dyes have a high solubility and pass trough the classic wastewater treatment plants without any transformation (Chung et al., 1993). This way, they are discharged in water courses which often are used as drinking water supply, thus the environment fate of dyes is of serious concern.

It is already known that azo compounds can be degraded by anaerobic processes to intermediates (Haugh et al., 1991; Kudlich et al., 1996). Anaerobic dye metabolites may be degraded aerobically (FitzGerald et al., 1995) and it is known that aerobic mixed bacteria communities, capable to metabolize anaerobic dye intermediates as sole source of carbon, have been isolated (Haugh et al., 1991).

The degradation of azo dyes, according to the literature (Cooper, 1995), is influenced by the number of sulfonated groups present in the dye molecule and metabolites. Sulfonic groups are pointed out as inhibitors for microbial attack (Leidner et al., 1979; Wuhrmann et al., 1980). However there is no complaint about sulfonated compounds in the environment and so, despite its poor biodegradability, at least some sulfonates are likely to be completely degraded (Cook et al., 1999).

Under anaerobic conditions azo compounds are reduced by cleavage of the azo bond (Seshadri et al., 1994) which is probably pH dependent (Weber et al., 1987):

$$
\mathrm{R}_{1}-\mathrm{N}=\mathrm{N}-\mathrm{R}_{2}+4 \mathrm{e}+4 \mathrm{H}^{+} \rightarrow \mathrm{R}_{1}-\mathrm{N}+\mathrm{R}_{2}-\mathrm{N}
$$

where $R_{1}$ and $R_{2}$ are phenyl and naphtol groups, respectively.

Pasti-Grigsby et al. (1992) studied the influence of substituents on azo dye biodegradability by using actinomycetes and fungi and analysed the possibility of enhancing the biodegradability of azo dyes by changing the chemical structure of commercial dyes by linking selected substituents into the dyes' chemical structures. They found significant degradation of azobenzene derivative dyes by the actinomycetes when the hydroxyl group had a specific (para) position relative to the azo linkage and at least two electron-releasing substituents (methoxy and/or one alkyl group) were in ortho position relative to the hydroxyl group. The fungus used in their studies showed extensively decolorization of several azo dyes. According to the literature azo dye reduction occurs exclusively under anoxic conditions (Chung et al., 1993). 
The rate of this partial degradation should be studied to find if it affects the degradation rate of the substrate used as sole carbon source. Several expressions have been proposed to describe the reduction of nitroaromatic compounds (Weber et al., 1987). A study of the reduction of azo dyes in anaerobic cultures was also performed by Dubin and Wright (1975) and they observed a zero order reduction kinetics with respect to the dye concentration. Investigations on reduction kinetics of a series of azobenzene derivatives substituted with various electron-donating and electron-withdrawing groups were also done by Weber and Wolfe (1987). For azo benzene degradation they found a first order decay rate. Wuhrmann $e t$ al. (1980) observed that the decolorization of a variety of dyes followed a first order kinetics at least in the initial phase of reaction. They also verified that azo reduction could even be inhibited by its reduction products, amine, nitrite and nitrate. The role of bacteria in reducing azo groups to carcinogenic compounds is of considerable concern (Brown et al., 1993). It is understood that anaerobic cleavage of azo linkage is just the initial step in the biodegradation of azo dyes (Games et al., 1977).

The aim of the present paper is to follow the degradation of a textile acid dye by an anaerobic mixed culture and to study the kinetic model involved. The dye degradation rate was investigated at different dye concentrations (up to $400 \mathrm{mg} / \mathrm{L}$ ) for a constant substrate concentration used as the sole carbon source. To understand the behaviour of anaerobic biological processes in the presence of xenobiotic compounds, as a first step of dye degradation, is also of great interest.

\section{MATERIALS AND METHODS}

\section{Batch Systems}

In these experiments five 1.5 liter vessels, equipped with a mechanical stirrer and four sample ports, were used. The sample ports were to bubble nitrogen gas during the first $15 \mathrm{~min}$ of reaction to remove the dissolved molecular oxygen from the system, for biogas collection, for sampling and for feeding. The reactors were maintained at $37 \pm 2^{\circ} \mathrm{C}$.

\section{Substrate and Inoculum}

Reactors were fed with a synthetic waste containing glucose as carbon source. Micronutrients and basic nutrients were added according to Wiegnant $e t$ al. 
(1985). A mixture of $80 \%(\mathrm{v} / \mathrm{v})$ of the synthetic waste and a $20 \%(\mathrm{v} / \mathrm{v})$ of anaerobic sludge with $35 \mathrm{gVSS} / \mathrm{L}$ was introduced in each reactor. The biomass used as inoculum was a seed sludge collected in a municipal wastewater treatment plant and acclimatised for six months in the laboratory.

A commercial azo dye was selected for this work: a sulfonated diazo dye, "Acid Red 73". It was dissolved in the synthetic medium in concentrations of $60,80,100,120,150,200,300$ and $400 \mathrm{mg} / \mathrm{L}$ and fed to the reactors. The synthetic waste supplemented with dye was analysed giving $1581 \mathrm{mg} / \mathrm{L}$ to $1965 \mathrm{mg} / \mathrm{L}$ for chemical oxygen demand (COD) and $16 \mathrm{mg} / \mathrm{L}$ to $25 \mathrm{mg} / \mathrm{L}$ for suspended solids (SS).

\section{Analytical Methods}

Samples were collected during the reaction time, up to 72 hours. Samples of $5 \mathrm{~mL}$ were withdrawn and filtered through $0.45 \mu \mathrm{m}$ glass microfiber membrane for analysis of soluble components. $\mathrm{pH}$, suspended solids (SS), volatile suspended solids (VSS) and chemical oxygen demand (COD) were determined according to the Standard Methods (Standard Methods, 1992). The color was measured by running ultraviolet-visible spectra on filtered samples. The wavelength of maximum absorbance in the visible region, $\lambda_{\max }$, is $510 \mathrm{~nm}$ for AR73. All the samples were analysed within two hours after collection to minimise the influence of light and oxygen.

\section{RESULTS AND DISCUSSION}

\section{Preliminary Tests}

Some preliminary tests with activated carbon granules were carried out to better understand the process of the dye removal, i.e., to find out which process takes place, adsorption or bioelimination. For these experiments two vessels were used, one with $48 \mathrm{~g}$ of granular activated carbon $(100 \mathrm{~mL})$, $100 \mathrm{mg} / \mathrm{L}$ of AR73 dissolved in the synthetic medium, and the other was inoculated with $200 \mathrm{~mL}$ of anaerobic biomass and $100 \mathrm{mg} / \mathrm{L}$ of dye AR73 dissolved in the synthetic medium. The total volume of the reaction mixture was 1 liter. Samples were gathered, filtered and then the colour measured at $\lambda_{\max }$. The evolution of the spectra in the ultraviolet-visible region was compared as well.

In the vessel with activated carbon a decrease of the peaks in the whole ultraviolet-visible region occurred as shown in Figure 1, which means 

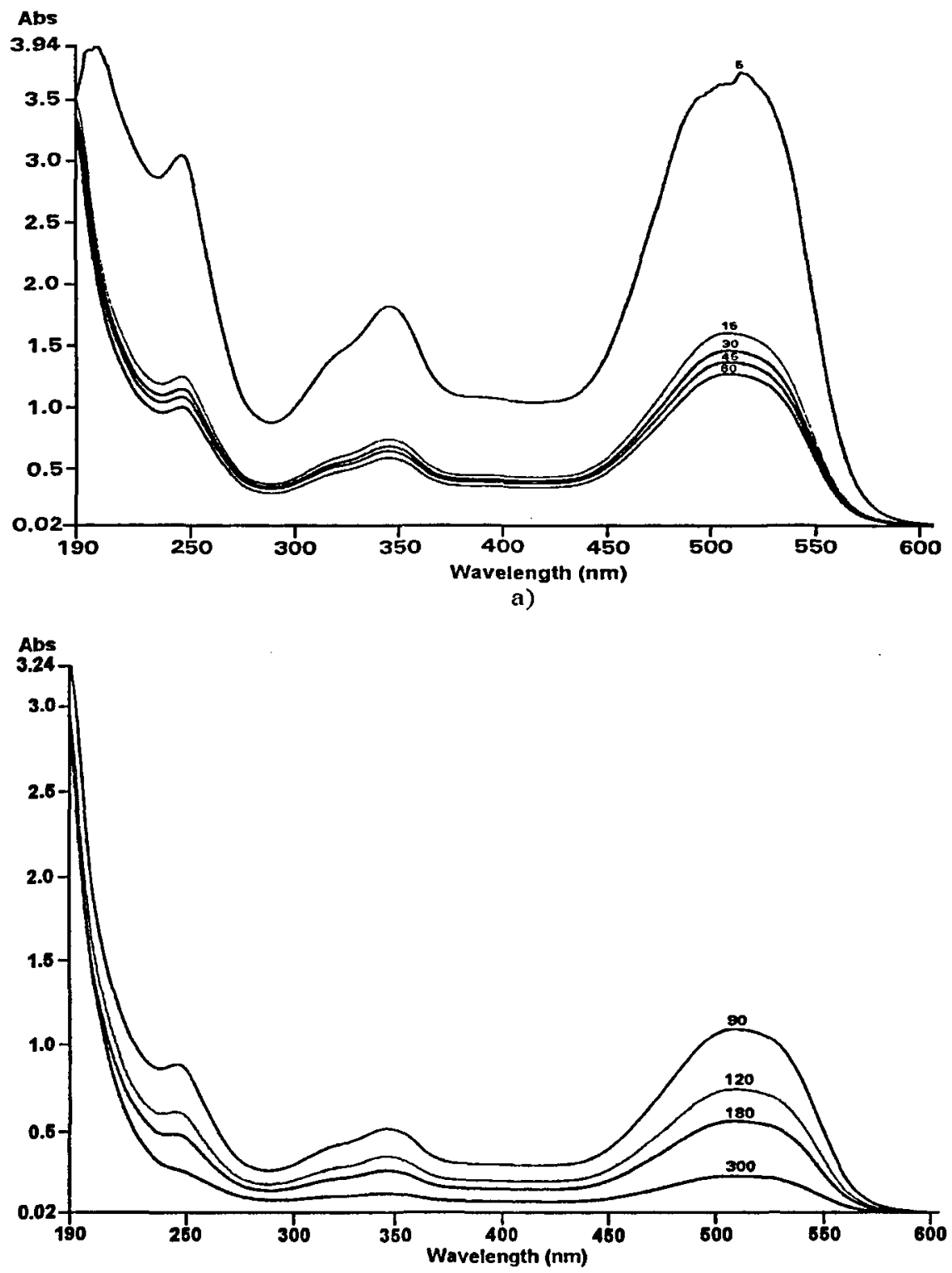

b)

FIGURE 1 Dye adsorption on activated granular carbon at (a) 5, 15, 30, 45 and 60 minutes; (b) $90,120,180$ and 300 minutes.

adsorption of the whole molecule of the dye. After 6 hours the dye had been removed almost entirely from the supernatant solution. In the vessel with 
Abs

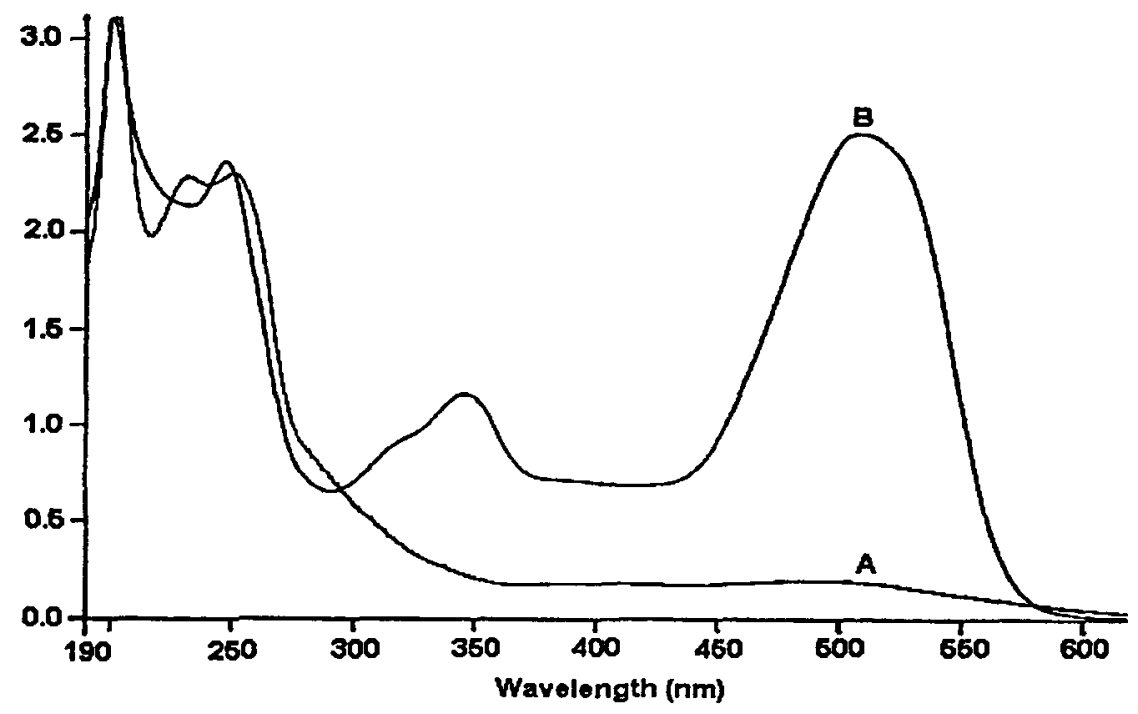

FIGURE 2 Spectra of the dye before (B) and after contact (A) with anaerobic biomass.

biomass the evolution of the spectra was significantly different and, after 24 hours the spectra were altered (Figure 2), indicating that the chemical structure of the dye was affected. These results showed that not only adsorption had occurred, as a first mechanism of the colour removal, but also a biotransformation of the dye molecule, due to the presence of anaerobic bacteria. Following these results some kinetics studies on colour removal were done.

\section{Main Tests}

The rate of degradation of organic matter easily metabolized (glucose) and degradation of dyes can be described by equations based on MichaelisMenten kinetics, in which enzymes of the biomass attack these compounds degrading them (e.g., reducing the azo group of the dye). According to the literature (MetCalf et al., 1991, Llabrés-Luengo et al., 1987), when the substrate concentration is low, Michaelis-Menten kinetics can be simplified and a first order model can be used to describe the substrate utilisation in biochemical reactions. It was also assumed that the biomass concentration remained constant during the time required for the process to take place.

Anaerobic decolorization takes place even for high dye concentrations. Removal efficiency was, on the average, higher than $90 \%$ even for dye 


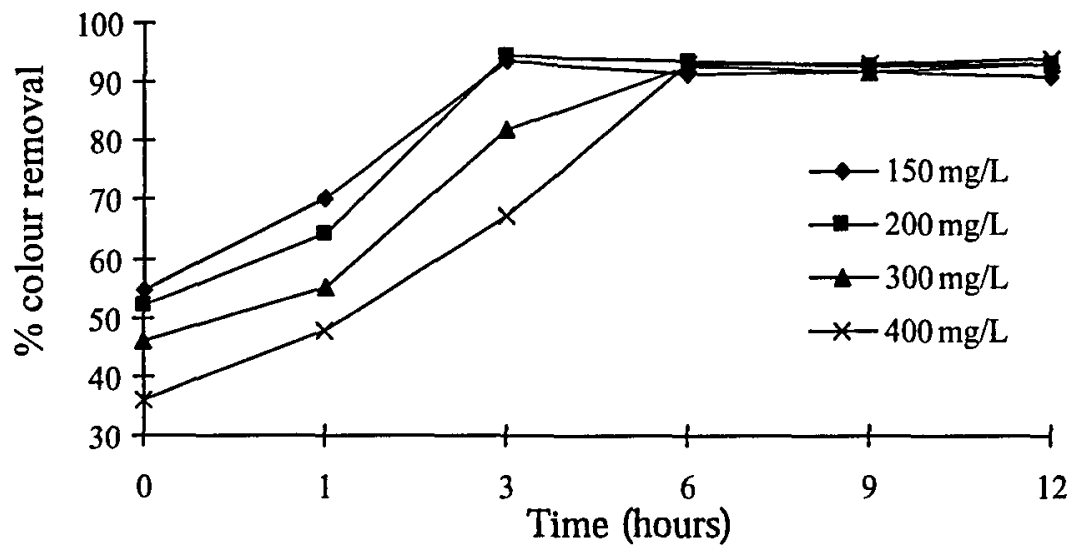

FIGURE 3 Percentage of colour removal of the dye Acid Red 73 at several dye concentrations.

concentrations of $400 \mathrm{mg} / \mathrm{L}$ (Figure 3). The time required to get a residual constant value of dye concentration increased with the concentration. As shown in Figure 3 dye decolorization occurred essentially in the first 6 hours of reaction, indicating that this process occurred faster than the degradation of glucose which took about 72 hours approximately (Figure 4). As observed in Figure 4, the percentage of COD removal decreased as dye concentration increased, which is certainly due to the dye/dye metabolites contribution to the total COD.

As the system is well homogenised, no significant resistance to mass transfer exists, so the dye degradation rate is mainly controlled by biochemical

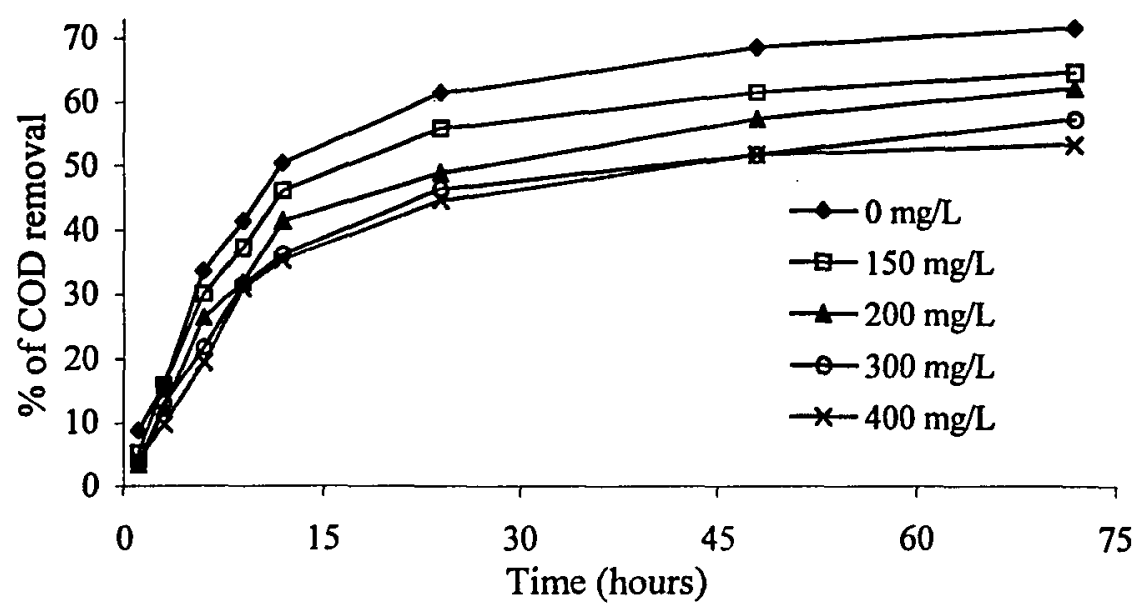

FIGURE 4 Percentage of COD removal in batch reactors at several dye concentrations. 
processes, and a kinetic equation similar to Michaelis-Menten model could be used as follows:

$$
-\frac{\mathrm{d} C}{\mathrm{~d} t}=\frac{\lambda(X) C}{\lambda_{c}+C}
$$

and

$$
r=-\frac{\mathrm{d} C}{\mathrm{~d} t}
$$

where

$r$ - dye degradation rate, $\mathrm{ML}^{-3} \mathrm{~T}^{-1}$

$C$ - dye concentration, $\mathrm{ML}^{-3}$

$X$ - biomass concentration, $\mathrm{ML}^{-3}$

$t-$ reaction time, $\mathrm{T}$

$\lambda(X)$ - kinetic constant or Michaelis-Menten constant, $\mathrm{ML}^{-3} \mathrm{~T}^{-1}$

$\lambda_{c}$ - half-saturation constant, $\mathrm{ML}^{-3}$.

Assuming the biomass concentration is constant, integration leads to the following equation:

$$
\lambda_{c} \ln \frac{C_{0}}{C}+\left(C_{0}-C\right)=\lambda(X)\left(t-t_{0}\right)
$$

where

$C_{0}-$ initial dye concentration, $\mathrm{ML}^{-3}$

$t_{0}$ - initial time, $\mathrm{T}$.

For low dye concentrations, i.e., $\lambda_{c} \gg C$ equation (1) could be simplified following a first order kinetics model (MetCalf et al., 1991; Llabrés-Luengo et al., 1987):

$$
\frac{\mathrm{d} C}{\mathrm{~d} t}=\lambda^{\prime} C
$$

where

$$
\lambda^{\prime}=\frac{\lambda(X)}{\lambda_{c}} .
$$

With the following initial conditions: for $t=0 \Rightarrow C=C_{0}$, integration gives

$$
C=C_{0} \mathrm{e}^{-\lambda^{\prime}\left(t-t_{0}\right)} \text {. }
$$

Results were regressed using an ENZFITTER software (Leatherbarrow, 1987). By fitting the proposed equations to the experimental results it was observed that for dye concentrations till $200 \mathrm{mg} / \mathrm{L}$ data follow a first order 

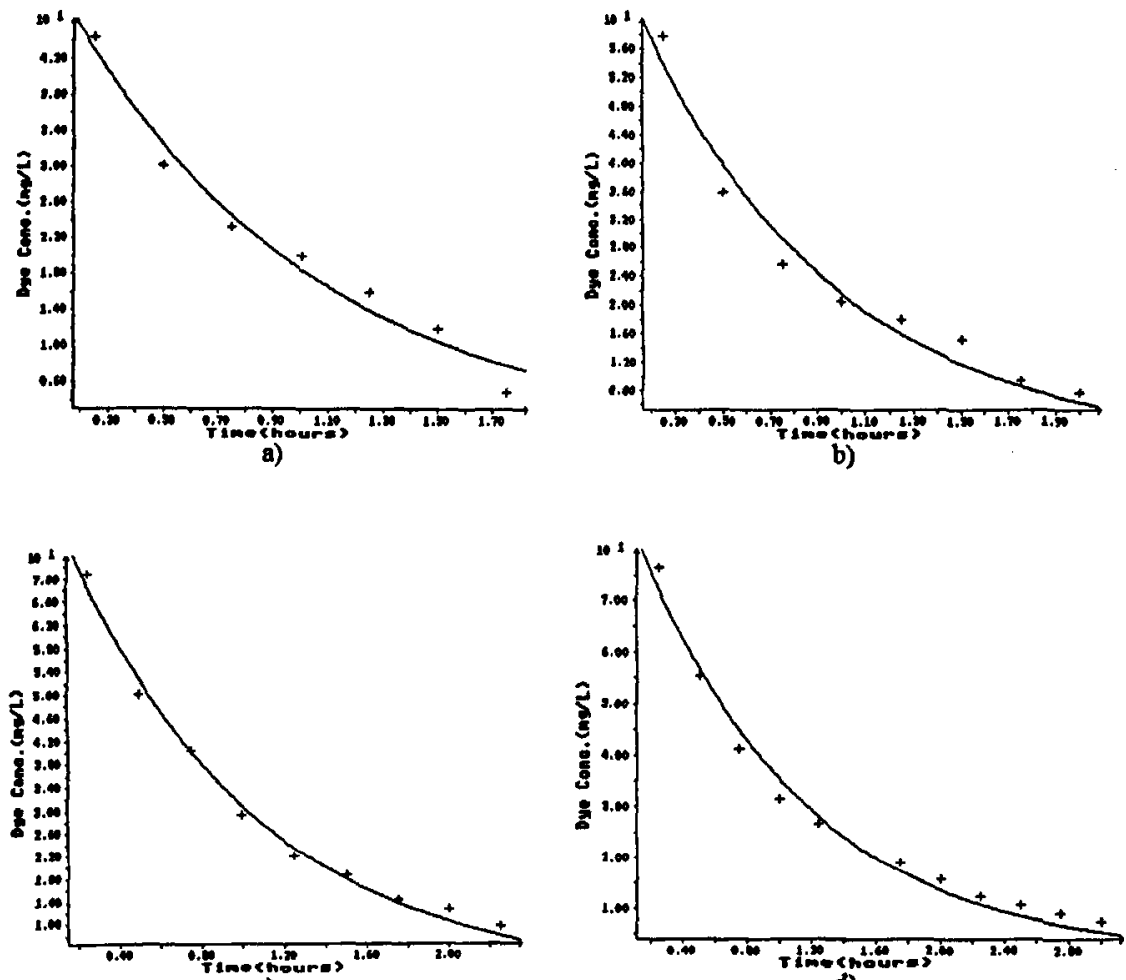

c)
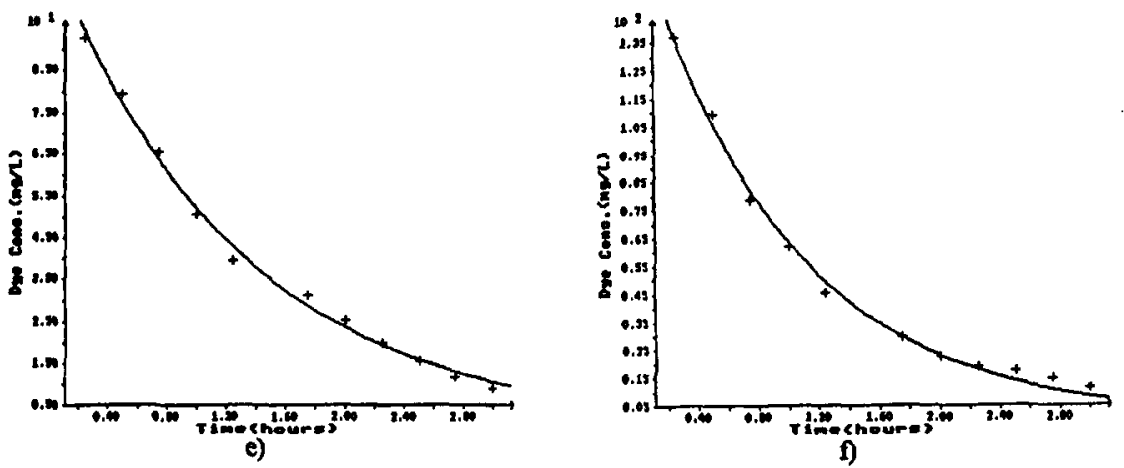

FIGURE 5 Kinetics fitting of anaerobic dye degradation for a dye concentration of: (a) $60 \mathrm{mg} / \mathrm{L}$; (b) $80 \mathrm{mg} / \mathrm{L}$; (c) $100 \mathrm{mg} / \mathrm{L}$; (d) $120 \mathrm{mg} / \mathrm{L}$; (e) $150 \mathrm{mg} / \mathrm{L}$; (f) $200 \mathrm{mg} / \mathrm{L}$.

kinetic model (equation (4)), as can be observed in Figure 5. Kinetic parameters values of $\lambda^{\prime}$ and $C_{0}$ are indicated in Table $\mathrm{I}$. 
TABLE I Kinetic parameters obtained for dye concentrations up to $200 \mathrm{mg} / \mathrm{L}$

\begin{tabular}{llcccccc}
\hline Kinetic paramters & \multicolumn{6}{c}{ Dye concentration $(\mathrm{mg} / \mathrm{L})$} \\
\cline { 3 - 8 } & & 60 & 80 & 100 & 120 & 150 & 200 \\
\hline \multirow{3}{*}{$\lambda^{\prime}\left(\mathrm{h}^{-1}\right)$} & Average & 1.26 & 1.30 & 1.00 & 0.82 & 0.78 & 0.77 \\
& Standard deviation & 0.30 & 0.36 & 0.20 & 0.18 & 0.16 & 0.22 \\
& Number of samples & 3 & 3 & 3 & 2 & 3 & 3 \\
& Average & 55.0 & 69.0 & 79.7 & 83.0 & 104.0 & 150.7 \\
$C_{0}(\mathrm{mg} / \mathrm{L})$ & Standard deviation & 9.2 & 7.8 & 10.5 & 12.7 & 11.0 & 22.5 \\
& Number of samples & 3 & 3 & 3 & 2 & 3 & 3 \\
\hline
\end{tabular}

Standard errors of the parameters were in general lower than $10 \%$, which indicate that is an acceptable fit, according to Leatherbarrow, 1987. Results obtained for $\lambda^{\prime}$ indicated (Table I) a general tendency to decrease with the increase of dye concentration, which means a decrease in rate degradation. This fact can be attributed to a probable inhibition factor that is being introduced by the dye/dye metabolites present in the reactional mixing.

For dye concentrations of $300 \mathrm{mg} / \mathrm{L}$ and $400 \mathrm{mg} / \mathrm{L}$ equation (2) was fitted with $t_{0}=0$ :

$$
t=\frac{1}{\lambda(X)}\left(C_{0}-C\right)+\frac{\lambda_{c}}{\lambda(X)} \ln \frac{C_{0}}{C} .
$$

Fitting experimental results for 300 and $400 \mathrm{mg} / \mathrm{L}$ of dye (Figure 6) led to the kinetic parameters shown in Table II. In this case the rate of decolorization decreases more rapidly than predicted by a first order reaction, which could be explained by the fact that the reduction products accumulated in the medium are responsible for some kind of inhibition.

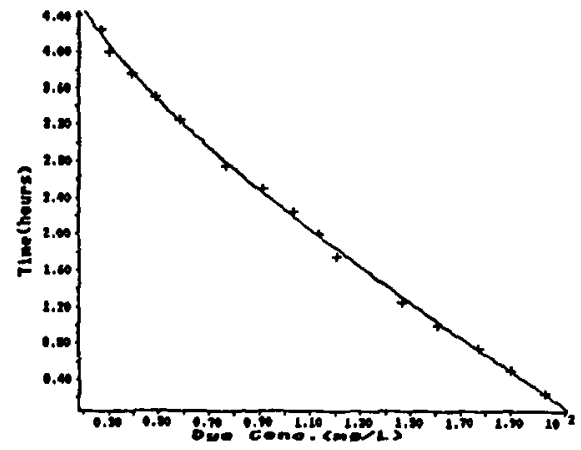

a)

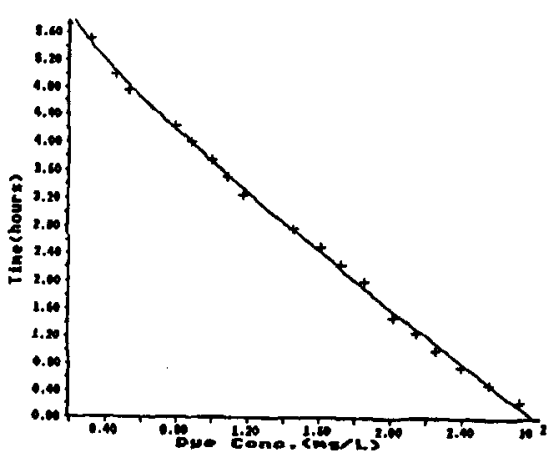

b)

FIGURE 6 Kinetics fitting of anaerobic dye degradation for a dye concentration of: (a) $300 \mathrm{mg} / \mathrm{L}$; (b) $400 \mathrm{mg} / \mathrm{L}$. 
TABLE II Kinetic parameters obtained for $300 \mathrm{mg} / \mathrm{L}$ and $400 \mathrm{mg} / \mathrm{L}$ of dye

\begin{tabular}{llcc}
\hline \multirow{2}{*}{ Kinetic parameters } & \multicolumn{2}{c}{ Dye concentration $(\mathrm{mg} / \mathrm{L})$} \\
\cline { 3 - 4 } & & 300 & 400 \\
\hline$\lambda(X)(\mathrm{mg} / \mathrm{L} . \mathrm{h})$ & Average & 65.5 & 60.0 \\
& Standard deviation & 0.7 & - \\
& Number of samples & 2 & 1 \\
$\lambda_{c}(\mathrm{mg} / \mathrm{L})$ & Average & 46.0 & 34.0 \\
& Standard deviation & 7.1 & - \\
& Number of samples & 2 & 1 \\
& Average & 198.5 & 290.0 \\
$C_{0}(\mathrm{mg} / \mathrm{L})$ & Standard deviation & 24.7 & - \\
& Number of samples & 2 & 1 \\
\hline
\end{tabular}

The kinetic parameters $\lambda(X)$ and $\lambda_{c}$ show a tendency to decrease with the dye concentration, even with the few results obtained (Table II). This behaviour had also been observed for the kinetic parameter $\lambda^{\prime}$ for dye concentrations up to $200 \mathrm{mg} / \mathrm{L}$ (Table I). According to the experimental results, the residual dye concentration was different from zero for each initial dye concentration, and it was also observed that their values increased as the initial dye concentration increased. This fact could likely be explained by the presence of dye metabolites that absorb at the same wavelength of the dye molecule itself.

Values of $C_{0}$ (Tables I and II) are in general lower than the initial dye concentration fed to the reactors, which indicates that adsorption occurs as a primary removal mechanism of the dye. This adsorption causes a decrease of the absorbance of the dye solution immediately upon contact with the bacteria suspension and was not included in the calculations of the kinetic parameters.

\section{CONCLUSIONS}

Although Dubin and Wright (1975) indicated a zero order kinetics for reduction of azo dyes, in the present work it was found, for concentrations up to $200 \mathrm{mg} / \mathrm{L}$, a first order kinetics decolorization rate according to Wuhrmann et al. (1980) and for concentrations of 300 and $400 \mathrm{mg} / \mathrm{L}$ a kinetics model similar to the Michaelis-Menten equation. This indicates that, despite of being a gratuitous process, anaerobic azo bond cleavage goes on until very low concentrations. However, it should also be pointed out that for dye concentrations higher than $200 \mathrm{mg} / \mathrm{L}$ the depletion rate of the dye is not so 
pronounced as in the case of lower dye concentrations, which is reproduced by a first order equation.

High dye concentrations seem not to cause biological inhibition in a significant extension, as well as its metabolic products. However, kinetic parameters $\lambda_{c}, \lambda(X)$ and $\lambda^{\prime}$, indicate a decrease tendency in their values (Tables I and II) as dye concentration increases, which may be interpreted as a small inhibition factor due to the dye/dye metabolites in the liquor mixture. Variations in these parameters obtained by fitting experimental results (Tables I and II) could be explained, among others factors, by the fact that some of them are not real constants, but indeed they depend on the mass of biomass present along the time.

As the process is complex and poorly understood, the proposed model is a simplified one with some limitations, but it is capable of predicting anaerobic dye degradation.

The dye studied contains two sulfonic groups that could also have an inhibitory effect (Wuhrmann et al., 1980). Also no significant differences were observed in biological degradation of glucose used as co-substrate when the dye was present.

Decolorization by reductive cleavage does not represent the complete degradation of the dye and, in terms of environment issues, the problem still remains, so the question of to find out conditions that cause complete biological oxidation of anaerobic metabolites in mineralised products is essential and is still to be solved.

\section{References}

Brown, M.A. and Vito, De, Predicting azo dye toxicity. Crit. Revi. Environ. Sci. Technol., 23, 249-324 (1993).

Chung, K.-T., Stevens, S.E. and Cerniglia, C.E., The reduction of azo dyes by the intestinal microflora. Crit. Rev. Microbiol., 18, 175-190 (1993).

Cook, A.M., Laue, H. and Junker, F., Microbila Desulfonation. FEMS Microbiol. Rev., 22, 399-419 (1999).

Cooper, P., Colour in Dyehouse Effluent, Society of Dyers and Colourists (1995).

Dubin, P. and Wright, K.L., Reduction of Azo Food Dyes in Cultures of Proteus Vulgaris. Xenobiotics, 5, 563-571 (1975).

Games, L.M. and Hites, R.A., Composition, treatment efficiency and environmental significance of dye manufacturing plant effluents. Anal. Chem., 49, 1433-1440 (1977).

Haugh, W., Schmidt, A., Nortemann, B., Hempel, D.C., Stolz, A. and Knackmuss, H.J., Mineralization of the Sulfonated Azo Dye Mordant Yellow 3 by a 6-Aminonaphthalene-2sulfonate-Degrading Bacterial Consortium. Appl. Environ. Microbiol., Nov., 3144-3149 (1991).

Kudlich, M., Bishop, P.L., Knackmuss, H.J. and Stolz, A., Simultaneous Anaerobic and Aerobic Degradation of the Sulfonated Azo Dye Mordant Yellow 3 by Immobilized Cells from a Naphthalenesulfonate-Degrading Mixed Culture. Appl. Microb. Biotechnol., 46, $597-603$ (1996). 
Llabrés-Luengo, P. and Mata-Alvarez, J., Kinetic Study of the Anaerobic Digestion of StrawPig Manure Mixtures. Biomass, 14, 129-142 (1987).

Leatherbarrow, R.J., Manual of Enzfitter, Elsevier Science Publishers BV (1987).

Leidner, H., Gloor, R., Wüest, D. and Wuhrmann, K., Xenobiotica (1979).

Michaelis, B.B. and Lewis, D.L., Sorption and toxicity of azo and triphenylmethane dyes to aquatic microbial populations. Environ. Toxicol. Chem., 4, 45-50 (1985).

Michaelis, B.B. and Lewis, D.L., Microbial transformation rates of azo and triphenylmethane dyes. Environ. Toxicol. Chem., 5, 161-166 (1986).

Metcalf and Eddy, Wastewater Engineering - Treatment, Disposal, Reuse, 3rd edn, McGraw Hill International Editions (1991).

Pasti-Grigsby, M.B., Paszczynski, A., Goszczynski, S. and Crawford, D.L., Infleunce of Aromatic Substitution Patterns on Azo Dye Degradability by Streptomyces spp. and Phanerochaete chryssosporium. Appl. Environ. Microbiol., Nov., 3605-3613 (1992).

Seshadri, S. and Bishop, P.L., Anaerobic Treatment of Selected Azo Dyes in Wastewater. Waste Manage., 14(2), 127-137 (1994).

Standard Methods for the Examination of Water and Wastewater, 16th edn, APHA, AWWA, WPCF-USA (1992).

Weber, E.J. and Wolfe, N.L., Kinetic Studies of the Reduction of Aromatic Azo Compounds in Anaerobic Sediment/Water Systems. Environ. Toxicol. Chem., 6, $911-919$ (1987).

Wiegnant, W.M. and Lettinga, G., Thermophilic Anaerobic Digestion of Sugars in Upflow Anaerobic Sludge Blanket Reactors. Biotechnol. Bioentg., 27, 1603-1607 (1985).

Wuhrmann, K., Mechsner, K. and Kappeler, T., Investigation on Rate-Determining Factors in the Microbial Reduction of Azo Dyes. European J. Appl. Microbiol. Biotechnol., 9, 325-338 (1980). 